\title{
A Survey on Dirofilaria immitis Occurence in Stray Dogs of Tabriz (Iran)
}

\author{
Ahmad Nematollahi ${ }^{1}$ and Mohammad Ali Javidi Barazandeh ${ }^{2}$ \\ ${ }^{1}$ Department of Parasitology, Faculty of Veterinary Medicine, University of Tabriz, Tabriz, Iran \\ ${ }^{2}$ Veterinary Practice, Tabriz, Iran
}

Received August 9, 2009

Accepted March 8, 2010

\begin{abstract}
To determine the prevalence of microfilariae Dirofilaria immitis (canine heart worm) infection in Tabriz (East-Azarbaijan province, Iran), blood samples from 63 male and 37 female stray dogs of six age groups ( $<1$ years, 1-3 years, 3-5 years, 5-7 years, 7-9 years and $>9$ years) were analyzed by means of the Knott method. Dirofilaria immitis infection was found in 30 of 100 tested dogs $(30 \%)$. Male dogs $(33.3 \%)$ were more infected than females $(24.3 \%)$, but this difference was not significant. Higher prevalence was found in $>9$ years old dogs than in other age groups, but this difference was not statistically significant. It would be useful to apply prevention measures to control Dirofilaria immitis infection in the canine population of Tabriz.
\end{abstract}

Dirofilariosis, dog, sex, age

Dirofilariosis is a disease of world wide distribution, but the most endemic areas are those with moderate, tropical and subtropical climates where mosquito populations are high and stable. Other regions with cold weather, with hot summers and with rivers, lakes and widely irrigated lands are also suitable for the development of the disease. Female mosquitoes serve as an intermediate host by sucking blood from a dog with circulating Dirofilaria immitis microfilaria (Montoya et al.1988). Dirofilaria immitis is commonly found in the pulmonary arteries and the right ventricle of dogs and other canines where it causes canine heartworm disease, but it also occurs in cats and humans. Several mosquito species are responsible for the transmission of the disease. The disease often has no clinical signs in mild infection, but with severe infection the affected animals show disorders in the circulatory system and in some cases progressive endarteritis may occur due to the mechanical effects of the parasite. Adult heartworms can cause several clinical symptoms and pathological changes in infected dogs, such as oedema, heart failure or even death (Soulsby 1982). The diagnosis of canine heartworm infection is based upon the detection of D. immitis circulating in blood or upon the detection of serum antibodies by serologic methods (Peribanez et al. 2001).

Endemic occurrence of $D$. immitis has been reported in the USA, Canada, South America, Africa, Australia, Asia and Europe (Yildirim et al. 2006). The prevalence of heartworm infection in dogs appears to have increased in recent years. This is due to a lack of prevention procedures and weak knowladge of dogs' owners (Lee et al. 1996).

This study was conducted to investigate the prevalence and epidemiological aspects of dirofilariosis in stray dogs from Tabriz in the northwest of Iran, which is one of the enzootic regions of $D$. immitis.

\section{Materials and Methods}

Study area

The study was conducted in Tabriz (northwest Iran). Tabriz is located in the East-Azarbaijan province $\left(36^{\circ} 43^{\prime}-\right.$ $39^{\circ} 25^{\prime} \mathrm{N}$ and $45^{\circ} 3^{\prime}-48^{\circ} 19^{\prime} \mathrm{E}$ ). The region is mountainous, with an altitude of $1351.4 \mathrm{~m}$. The climate is temperate with relatively hot and dry summers and cold winters.

Address for correspondence:

Dr. Ahmad Nematollahi

Department of Parasitology, Faculty of Veterinary Medicine

University of Tabriz, Tabriz, Iran
Phone: +984 113862420

Fax: +984113357834

E-mail: anemat@tabrizu.ac.ir

http://www.vfu.cz/acta-vet/actavet.htm 
Animals

In a period of one-year, from 2005 to 2006, a total of 100 blood samples were taken from the cephalic vein of 63 male and 37 female stray dogs by vacuum tube including anticoagulant (sodium citrate). The age of animals was recorded. The animals were divided into six age groups ( $<1$ years, 1-3 years, 3-5 years, 5-7 years, 7-9 years and $>9$ years) .

Laboratory procedures

In the parasitology laboratory, all blood samples were examined using the Knott method (Soulsby 1982). Morphometric identification of microfilariae was based on criteria reported by Ettinger (2000). The length and width of microfilariae in each sample were measured using an ocular micrometer with $\times 400$ magnification.

\section{Necropsy}

In order to diagnose occult dirofilariosis, after obtaining the local Ethics Committee approval 13 dogs were selected randomly subjected to necropsy and then pulmonary arteries and hearts were searched for the presence of adult $D$. immitis.

\section{Statistical analysis}

Pearson's chi-square $\left(\chi^{2}\right)$ test and Fisher test was performed to compare prevalence related to sex and age categories. Statistical comparisons were carried out using SPSS 10.0 statistical software.

\section{Results}

Table 1. The prevalence of microfilariae of Dirofilaria immitis in blood of dogs

\begin{tabular}{|l|c|c|c|}
\hline Sex & No. tested & No. positive & \% of positive \\
\hline Male & 63 & 21 & 33.3 \\
\hline Female & 37 & 9 & 24.3 \\
\hline
\end{tabular}

Table 2. The prevalence of microfilariae of Dirofilaria immitis in blood of dogs according to age

\begin{tabular}{|c|c|c|c|}
\hline Age groups & No. tested & No. positive & \% of positive \\
\hline$<1$ year & 5 & - & - \\
\hline $1-3$ & 15 & 2 & 13.3 \\
\hline $3-5$ & 24 & 7 & 29.16 \\
\hline $5-7$ & 28 & 10 & 35.7 \\
\hline $7-9$ & 18 & 7 & 38.8 \\
\hline$>9$ & 10 & 4 & 40 \\
\hline
\end{tabular}

compared Only in one dog negative for $D$. immitis by Knott method adult worms were found by necropsy.

\section{Discussion}

The results of this study showed that $30 \%$ of stray dogs in Tabriz were infected with microfilariae of Dirofilaria immitis. In Iran, different prevalences were reported in previous studies: $60.8 \%$ in Shahsavar, 26.7\% in Meshkin-Shahr and 8.4\% in Tabriz (Sadighian 1969; Javidi 2003). All the mentioned studies used the Knott test method. The differences obtained in our and previous studies might be related to factors such as mosquito population density, mosquito fertility, mosquito species and environmental temperature. Close to Iran, D. immitis was reported from Turkey with the prevalence of 9.3\% in Ankara (Oge et al. 2003) and 9.6\% in Kaysari (Yildrim et al . 2006). The highest infestation in Asia was reported in Japan with $62.8 \%$ prevalence (Tada et al. 1991). The prevalence in our study is higher than in Turkey and Korea $(10.2 \%)$ but lower than in Japan (47\%) and Taiwan $(55 \%)$ (Tada et al. 1991; Lee et al. 1996; Fan et al. 2001; Yildirim 2006).

The results of the present study revealed that there is no significant difference in sex. 
This finding is similar to other studies in Iran and USA, but a study reported from USA and another one from Spain showed significantly higher prevalence in male dogs (Montoya et al. 1988; Wixsom et al. 1991). Since dirofilariosis has a higher prevalence rate in outdoor male dogs, this difference is probably due to different management methods of dog keeping.

The results of this study also showed that dogs above the age of 9 years were more infected than other age groups, but this difference was not significant. Similar findings were reported previously by several researchers in Iran and other countries (Fan et al. 2001; Javidi 2003). Risk of infection in dogs probably lasts for whole life and the likelihood of acquiring $D$. immitis infection increases with the time of exposure to the mosquitoes. Thus, older dogs have more time and opportunities to become infected with heartworm (Yildirim 2006).

The results of Ranjbar-Bahadori's study (2007) showed that Knott method has a high sensitivity and specifity compared to commercial antigen detection kit. That study showed that although sensitivity of antigen detection test was higher compared to the Knott method, the differences were not significant.

In our study, only microfialariae of $D$. immitis were found in dogs from Tabriz, but other authors reported presence of both microfilariae Diptalonema reconditum and Dirofilaria immitis in dogs from the same area (Javidi 2003).

In conclusion, infestation by Dirofilaria immitis in stray dogs in Tabriz is high and therefore treatment and prophylaxis are needed to decrease the risk of the disease. This research serves as a base line for future studies on treatment or prophylaxis of dirofilariosis in dogs in Tabriz.

\section{Acknowledgment}

This study was financially supported by the University of Tabriz.

\section{References}

Acevedo RA, Ciencias L, Theis JH, Kraus JF, Longhurst WM 1981: Combination of filtration and histochemical stain for detection and differentiation of Dirofilaria immitis and Dipetalonema reconditum in the dog. AJVR 42: $537-540$

Ettinger SJ, Feldman EC 2000: Dirofiariosis. In: Veterinary Internal Medicine. W.B. Saunders, Philadelphia, USA, pp. 939-940

Fan CK, Su KE, Lin YH, Liao CW, Du WY, Chiou HY 2001: Seroepidemiologic survey of Dirofilaria immitis infection among domestic dogs in Taipei City and mountain aboriginal districts. Vet Parasitol 102: 113-120

Javidi MA 2003: The survey on Infestation of stray dogs in Tabriz to filarial. DVM Thesis, Azad University, Tabriz, $98 \mathrm{p}$.

Lee JC, Lee CY, Shin SS, Lee CG 1996: A survey of canine heartworm infections among German shepherds in South Korea. Kor J Parasitol 34: 225-231

Montoya JA, Morales M, Ferrera O, Molina JM, Corbera JA 1988: The prevalence of Dirofilaria immitis in Gran Caliaria, Canary Islands, Spain. Vet Parasitol 75: 221-226

Oge HA, Doganay S, Yildirim A 2003: Prevalence and distribution of Dirofilaria immitis in domestic dogs from Ankara and vicinity in Turkey. DTW 110: 69-72

Peribanez MA, Lucientes J, Arce S, Morales M, Castillo JA, Gracia MJ 2001: Histochemical differentiation of Dirofilaria immitis, Dirofilaria repens and Acanthocheilonema dracunculoides microfilariae by staining with a commercial kit, Leucognost-SP. Vet Parasitol 102: 173-175

Ranjbar-Bahadori S, Eslami A, Bokaie S 2007: Evaluation of different methods for diagnosis of Dirofilaria immitis. Pakistan J Biol Sci 10: 1938-1940

Sadighian A 1969: Helminth parasites of stray dogs in Shahsavar, Iran. J Helminthol 2: 372-374

Soulsby EJL 1982: Nematoda. In: Helminths, Arthropods and Protozoa of domesticated animals, Baillière Tindall, London, pp. 307-311

Tada Y, Ohta T, Soohara S 1991: Helminths infection dogs in Shiga, Japan. J Vet Med Sci 53: 359-360

Wixsom MJ, Green SP, Corwin RM 1991: Dirofilaria immitis in coyotes and foxes in Missouri, USA. J Wildl Dis 84: $246-248$

Yildirim A, Ica A, Atalay O, Duzlu O, Inci A 2006 : Prevalence and epidemiologic aspect of Dirofilaria immitis in dogs from Kayseri province, Turkey. Res Vet Sci 82: 358-363 
